\title{
Gender, Age, previous Myocardial Infarction, and Personality as Predictors of Anxiety in Patients after Myocardial Infarction
}

\section{Libova (Lubica Libova)ำ P. Minarik (Peter Minarik)², A. Solgajova (Andrea Solgajova) $^{3}$, T. Sollar (Tomas Sollar) ${ }^{4}$, D. Zrubcova (Dana Zrubcova) ${ }^{3}$, J. Turzakova (Jana Turzakova) ${ }^{5}$, G. Vorosova (Gabriela Vororsova) ${ }^{3}$}

${ }^{1}$ Department of Nursing, Faculty of Health and Social Work, Nové Zámky, Original Article St. Elizabeth University of Health and Social Work Bratislava, Slovenska 11, 94052 Nove Zamky, SK.

${ }^{2}$ Department of Urgent Health Care, Faculty of Social Sciences and Health Care, CPU in Nitra, Kraskova 1, 94974 Nitra, SK.

${ }^{3}$ Department of Nursing, Faculty of Social Sciences and Health Care, CPU in Nitra, Kraskova 1, 94974 Nitra, SK.

${ }^{4}$ Department of Psychological Sciences, Faculty of Social Sciences and Health Care, CPU in Nitra, Kraskova 1, 94974 Nitra, SK.

${ }^{5}$ Institute of Applied Psychology, Faculty of Social Sciences and Health Care, CPU in Nitra, Kraskova 1, 94974 Nitra, SK.

\section{E-mail address:}

lubica.libova@gmail.com

\section{Reprint address:}

\section{Lubica Libova}

Department of Nursing, Faculty of Health and Social Work

Nove Zamky

St. Elizabeth University of Health and Social Work Bratislava

Slovenska 11

94052 Nove Zamky

Slovakia

Source: Clinical Social Work and Health Intervention

Volume: 12

Issue: 3

Pages: 97 - 103

Cited references: 32

\section{Reviewers:}

Roberto Cauda

Institute of Infectious Diseases, Catholic University of the Sacred Heart, Rome, IT

Jirina Kafkova

MSF, Freetown, SL

\section{Keywords:}

Anxiety. Myocardial Infarction. Hospitalized Patients. Personality. Gender. Age.

\section{Publisher:}

International Society of Applied Preventive Medicine i-gap

CSWHI 2021; 12(3): 97 - 103; DOI: 10.22359/cswhi_12_3_17 C Clinical Social Work and Health Intervention 


\section{Abstract:}

Objectives: The first research objective was to study the prevalence of anxiety in patients after myocardial infarction; next objective was to investigate demographic and personality predictors of anxiety.

Methods: 100 hospitalized patients after myocardial infarction were studied. The Mini IPIP tool was used for the evaluation of personality characteristics and HADS-A scale was used for the evaluation of anxiety. Multiple regression was used as an analytical framework.

Results: The prevalence of significant anxiety among patients after myocardial infarction was high, almost one half of patients reported abnormal anxiety symptoms. Female gender, higher age, higher neuroticism and lower conscientiousness explain $66 \%$ of the variability of anxiety. Personality traits of extraversion, openness, agreeableness and previous myocardial infarctions do not show as significant predictors.

Conclusion: The prevalence of anxiety in the group of patients after myocardial infarction is high. Knowing predictors of anxiety is important for better provision of care.

In general, anxiety is defined as an unpleasant mental status that is accompanied by anticipation of threat; an individual is in a state of anticipation of danger and experiences a stressful situation $(1,2)$. Anxiety often occurs in patients after myocardial infarction (MI) and affects their quality of life and overall status (3). The prevalence of anxiety in patients after MI is rather high; it is stated in up to a half of hospitalized patients (4-6). According to the authors (7), anxiety occurred in $10 \%$ of hospitalized patients after MI even at a higher level than in psychiatric patients with anxiety. The highest levels of anxiety are found in the first days after MI and decrease approximately after 3 or 4 months $(7,8)$. According to the findings by the authors (9), the highest levels of anxiety in patients after MI were found at ICUs during patients' admissions and immediately after their transfers to the department.

Anxiety after MI is accompanied by: multiple complications; particularly recurrent MI or death $(4,10)$; increased mortality and morbidity after revascularization after MI (11); longer recuperation (12); disability (13). Many complications occur already during patients' hospitalizations $(14,15)$. Moser, et al. (14) confirm that anxiety is an individually related factor with occurrence of cardiac complications after MI independent of the influence by other demographic or clinical factors. According to many authors, it is neces- sary to study not only biological but also psychological factors because they influence morbidity and mortality, too $(4,16)$.

After MI, anxiety is more common in women $(6,17)$. Some authors state a relationship between anxiety after MI and: severity of the disease; duration of hospitalization (18); a previous acute coronary syndrome (19); other intercurrence diseases such as diabetes mellitus; education and social support $(20,21)$; a history of angina pectoris (6). On the contrary, Crowe et al. (7) state that anxiety in patients after MI assessed at different times does not relate to any demographic (gender, education, occupation) or clinical factors (severity of MI, previous MI).

A less studied research area in relation to anxiety in patients after MI is an influence of personality traits. Crowe, et al. (7) state that in 14\% of patients after MI anxiety was present as their personality trait. Rodin et al. (22) state that anxiety was present in up to $16-25 \%$ of patients after MI before MI occurred in them.

Related to an assumed clinical significance of the occurrence of anxiety in patients after MI, further research is needed, particularly because of inconsistent results of the previous studies $(23,24)$.

The first study objective was to study the prevalence of anxiety in patients after myocardial infarction. Next objective was to investigate demographic and personality predictors of anxiety. 


\section{Methods and Materials}

\section{Data Collection}

Cross-section type of research plan was used. Hospitalized patients in the cardiology department with the diagnosis Acute Myocardial Infarction were studied. The sampling criteria were: being after coronary-graphic examination; hospitalization minimum 72 hours after MI; lucid consciousness; respondent's informed consent.

The sample consisted of 100 respondents, including $50 \%$ of men. The respondents' age ranged from 25 to 80 years $\left(\mathrm{M}_{\mathrm{age}}=54.58\right.$; $\mathrm{SD}_{\mathrm{age}}=14.6$ ). For $16 \%$ of the patients it was the first MI; in $84 \%$ previous MI occurred; in 54\% one MI occurred before; in $24 \%$ two MIs occurred; in $6 \%$ three MIs occurred before. Research was held from November 2016 to February 2017. Trained nurses and a psychologist administered the scales $72 \mathrm{hrs}$ after MI. Research was conducted after the approval of Ethical Committee.

\section{Instruments}

Hospital Anxiety and Depression Scale (HADS) was used for assessment of anxiety and depression (25). This fourteen-item scale is assessing the mental state in the last week. One part of the scale - HADS-A was used for the evaluation of anxiety. A four-point scale was used. The sum of all 7 items was used in the analysis. For the anxiety levels, three levels were used: without anxiety (sum score 0-7); borderline anxiety (sum score 8-10); severe anxiety (sum score 11-21) (26). Validity and reliability of the instrument is well documented (27). The sum score with good reliability ( $\alpha=0.86)$ was used.

International Personality Item Pool (mini IPIP) was used for assessment of personality. The questionnaire follows Big 5 Theory for assessing 5 traits Neuroticism; Extraversion; Openness; Conscientiousness; Agreeableness. 20 items, 4 for each trait uses five-point liker scale were used (28). The sum scores show acceptable to good reliability $(\alpha=0.63-0.88)$.

Table 1 Models of predictors of anxiety in patients after myocardial infarction

\begin{tabular}{|c|c|c|c|c|}
\hline & $\mathrm{R}$ & Adj $R^{2}$ & $\mathrm{~F}$ & $\mathrm{P}$ \\
\hline Model 1 (Gender, Previous myocardial infarction, Age) & 0.549 & 0.280 & 13.70 & $<.001$ \\
\hline $\begin{array}{c}\text { Model } 2 \text { (Gender, Previous myocardial infarction, Age, } \\
\text { Neuroticism, Extraversion, Openness, } \\
\text { Agreeableness, Conscientiousness) }\end{array}$ & 0.830 & 0.661 & 24.92 & $<.001$ \\
\hline
\end{tabular}

Legend: Dependent variable: Anxiety (HADS - Anxiety)

Table 2 Coefficients of predictors for Model 1 and Model 2

\begin{tabular}{|c|c|c|c|c|c|c|}
\hline \multirow{2}{*}{\multicolumn{2}{|c|}{ Model 1 Gender }} & B & SE (B) & $\beta$ & $\mathrm{t}$ & p \\
\hline & & 0.451 & 0.144 & 0.277 & 3.130 & .002 \\
\hline \multirow{2}{*}{ Model 1} & Previous myocardial infarction & 0.165 & 0.101 & 0.156 & 1.645 & .103 \\
\hline & Age & 0.019 & 0.005 & 0.331 & 3.388 & .001 \\
\hline \multirow[t]{8}{*}{ Model 2} & Gender & 0.473 & 0.111 & 0.290 & 4.250 & .000 \\
\hline & Previous myocardial infarction & 0.117 & 0.073 & 0.111 & 1.612 & .110 \\
\hline & Age & -0.013 & 0.005 & -0.228 & -2.633 & .010 \\
\hline & Neuroticism & 0.099 & 0.029 & 0.365 & 3.430 & .001 \\
\hline & Extraversion & -0.034 & 0.023 & -0.168 & -1.515 & .133 \\
\hline & Openness & -0.019 & 0.027 & -0.073 & -.728 & .468 \\
\hline & Agreeableness & -0.020 & 0.019 & -0.095 & -1.081 & .282 \\
\hline & Conscientiousness & -0.072 & 0.028 & -0.284 & -2.588 & .011 \\
\hline
\end{tabular}

$B$ - the unstandardized beta, $S E(B)$ - the standard error for the unstandardized beta, $\beta$ - the standardized beta 


\section{Statistical Analyses}

IBM SPSS Statistics 20 for data analysis was used. Descriptive characteristics and the means of multiple regression was used. Anxiety was used as dependent variable. Gender, previous MI, age, personality traits were studied as independent variables. The hierarchical version of regression analysis which evaluates independent variables in groups was used (29).

\section{Results}

$47 \%$ of patients after myocardial infarction were classified as abnormal for anxiety, $29 \%$ of patients were classified as borderline and together $76 \%$ of patients after MI could be evaluated as anxious according to HADS-A criteria. The raw score of HADS-A was studied as dependent variable in all studied models.

In the first model where gender, previous MI and age were studied as predictors of anxiety in patients after MI was statistically significant $(\mathrm{F}$ $=13.70 ; \mathrm{p}<.001$, Adj $\left.\mathrm{R}^{2}=0.28\right)$; variables explained approximately $30 \%$ anxiety (Table 1 ).

Anxiety was significantly predicted by gen$\operatorname{der}(\beta=0.277, \mathrm{p}=.002)$ and age $(\beta=0.331, \mathrm{p}=$ .001 ; Table 2, Model 1) with lower anxiety for younger patients and men. Previous MI was not a significant predictor of anxiety in patients after MI $(\mathrm{p}=0.10)$.

In the second model, personality factors (of the Five-Factor model) were added to the 3 previously studied factors (gender, age, previous MI). Also this model was statistically significant $\left(\mathrm{F}=24.92 ; \mathrm{p}<.001, \mathrm{Adj} \mathrm{R}^{2}=0.66\right)$ and the studied variables explain $66 \%$ of anxiety in the patients after MI (Table 1). When personality variables were added to the analysis, the prediction of the model improved by ca. $38 \%$ and the change is also statistically significant $\left(\mathrm{p}_{(\mathrm{F} \text { Change })}<0.001\right)$.

Ass in the first model, gender and age are statistically significant predictors of anxiety. From the five studied personality predictors, anxiety was significantly predicted by neuroticism $(\beta=$ $0.365, \mathrm{p}=.001)$ and by conscientiousness $(\beta=-$ $0.284, p=.011$; Table 2, Model 1). Higher anxiety is connected with low Conscientiousness and high Neuroticism.

\section{Discussion}

Anxiety after MI is a frequently studied issue. The results of various studies unambiguously confirm that the prevalence of anxiety is even higher than the prevalence of depression (7) in more than half of hospitalized patients after MI $(4,5,9)$. According to Crowe et al. (7), up to $69 \%$ of patients after MI need an intervention to reduce psychological difficulties during their hospitalization. Sarkar et al. (6) confirmed anxiety symptoms in $48.5 \%$ of patients and anxiety as a disorder in more than $25 \%$ of patients after MI. In patients after MI, we found anxiety in $76 \%$ of the patients; severe anxiety was present in 47\%; borderline anxiety in $29 \%$ of the patients. Our findings support statements by authors (7) who state that patients after MI are at risk of symptoms of mental illnesses. Furthermore, the authors state that anxiety in patients after MI is a barrier in follow-up care; they also emphasize the importance of psychological interventions with focus on early detection of anxiety $(3,6,7)$.

The importance of psychological support in care for patients with cardiovascular diseases also is emphasized by the authors (11); they state that anxiety in patients after revascularization after MI closely relates to increased mortality and morbidity. The relationship between psychological problems after MI and cardiac complications also is stated by other authors $(4,5)$; some of the complications occur already during patients' hospitalization (15). Moser and Dracup (30) specify that anxiety after MI relates particularly to ischemic complications and arrhythmia. In another study (14), regardless of other factors (such as clinical and demographic), they unambiguously support a relationship between anxiety and complications; specifically recurrent chest pain; ventricular arrhythmia; congestive heart failure; recurrent chest pain with ischemia; ventricular arrhythmia requiring intervention; recurrent MI.

In the next part, we analysed the relationship between gender, age and previous MIs and anxiety after MI. We found that all three factors together explain $30 \%$ of the variability of anxiety after MI. Female gender and higher age were proved as statistically significant predictors of anxiety.

In their findings, Sarkar et al. (6) and Young \& Kahana (17) also state that anxiety after MI relates more to female gender. More frequent anx- 
iety in females is stated also in other clinical samples of patients, for example after cerebrovascular accidents (27). Female gender was stated as one of the predictable risk factors for anxiety in patients after cerebrovascular accidents even 3 years later (31). Despite many studies, findings on the relationship between gender and anxiety in patients after MI are still inconsistent and require further research.

The studies focused on examining the relationship between age and anxiety after MI are lacking. In our findings, higher age appears as a predictor of anxiety in patients after MI. On the contrary, findings on anxiety in patients after cerebrovascular accidents show that the prevalence of the highest anxiety levels is in younger patients (27); therefore, further research in this area is necessary.

Our findings do not prove previous MIs as a statistically significant predictor of anxiety after MI. The same findings are stated also by Crowe et al. (7).

In the second part of the analysis we studied other predictors of anxiety after MI. We added the personality factors of the Five-Factor model to the 3 studied factors (gender, age, previous MIs). We used the recommendations of authors (32) who state there is a lack of studies focused on examination of psychological factors related to adherence in patients with acute coronary syndrome; furthermore, they found that personality is a key factor contributing to non-adherence. In our study, we found that such related factors (gender, age, previous MIs, personality traits) explain up to $66 \%$ of the variability of anxiety after MI. From the five studied personality traits, higher Neuroticism and lower Conscientiousness appear as predictors of anxiety in patients after MI. Based on these findings, we assume that personality influences morbidity and mortality $(3,4)$. This finding can relate to the fact that anxiety can be present in up to $16-25 \%$ of patients after MI before MI occurs in them (8), i.e. anxiety can result in heart diseases.

\section{Conclusion}

Patients after MI often experience anxiety which appears as a problem in care. We found no negligible relationship between anxiety and female gender, higher age, and personality traits Neuroticism and Conscientiousness. These pre- dictors explain possible anxiety after MI. The identification of these predictors is helpful for early detection of anxiety after MI followed by early interventions for its reduction. Further study on other demographic, clinical and psychological predictors in mutual combination is highly recommended.

\section{Acknowledgments}

Research was conducted under the project VEGA No 1/0418/19 "Coping Strategies in Recovery After Stroke".

\section{Conflict of interest}

We state there are not known conflicts of interest for any of the authors.

\section{References}

1. PRASKO J (2004) Anxiety disorders. In: Hőschl C, Libiger J, Svestka J, editors. Psychiatry. Prague: Tigis; pp. 494-505.

2. HERETIK A SR. (2007) Anxiety (neurotic) disorders. In: Heretik A sr, Heretik A jr a kol, editors. Clinical psychology. Nove Zamky: Psychoprof ;. pp. 217-42.

3. MAYOU RA, GILL D, R TD, DAY A, HICKS N, VOLMINK J, ET AL. (2000) Depression and anxiety as predictors of outcome after myocardial infarction. Psychosom Med.; 62(2): pp. 212-9.

4. FRASURE-SMITH N, LESPERANCE F, TAJAJIC M (1994) Depression following myocardial infarction - impact on 6-month survival. JAMA J Am Med Assoc.;271(14): pp. 1081-2.

5. VAN MELLE JP, DE JONGE P, SPIJKERMAN TA, TIJSSEN JGP, ORMEL J, VAN VELDHUISEN DJ, ET AL. (2004) Prognostic association of depression following myocardial infarction with mortality and cardiovascular events: meta-analysis. Psychosom Med.;66(6): pp. 814-22.

6. SARKAR S, CHADDA RK, KUMAR N, NARANG R (2012) Anxiety and depression in patients with myocardial infarction : findings from a centre in India. Gen Hosp Psychiatry. Elsevier Inc.;34(2): pp.160-6.

7. CROWE JM, RUNIONS J, EBBESEN LS, OLDRIDGE NB, STREINER DL (1996) Anxiety and depression after acute myocardial infarction. Hear Lung.;25(2): pp.98-107. 
8. LLOYD GG, CAWLEY RH (1983) Distress or illness? A study of psychosocial symptoms after myocardial infarction. Br J Psychiatry.;142(2):120-5.

9. CAY EL, VETTER N, PHILIP AE, DUGARD P (1972) Psychological status during recovery from an acute heart attack. $J$ Psychosom Res.; 16(6): pp. 425-35.

10. LADWIG KH, KIESER M, KÖNIG J, BREITHARDT G, BORGGREFE M (1991) Affective disorders and survival after acute myocardial infarction. Results from the post-infarction late potential study. Eur Heart J.;12(9): pp. 959-64.

11. CARNEIRO AF, TELLES MATHIAS LAS, RASSI JÚNIOR A, DE MORAIS NS, GOZZANI JL, DE MIRANDA AP (2009) Evaluation Of Preoperative Anxiety And Depression In Patients Undergoing Invasive Cardiac Procedures. Brazilian J Anesthesiol. Elsevier;59(4): pp. 431-88.

12. MAELAND JG, HAVIK OE (1989) Use of health services after a myocardial infarction Use of Health Services after a Myocardial Infarction. Scand J Soc Med. 9; 17: pp. 93-102.

13. STERN MJ, PASCALE L, MCLOONE JB (1976) Psychosocial adaptation following an acute myocardial infarction. $J$ Chronic Dis.;29(8): pp. 513-26.

14. MOSER DK, RIEGEL B, MCKINLEY S, DOERING L V, AN K, SHEAHAN S (2007) Impact of anxiety and perceived control on in-hospital complications after acute myocardial infarction. Psychosom Med.;69(1): pp.10-16.

15. HUFFMAN JC, SMITH FA, BLAIS MA, JANUZZI JL, FRICCHIONE GL (2008) ;Anxiety, independent of depressive symptoms, is associated with in-hospital cardiac complications after acute myocardial infarction. J Psychosom Res. Elsevier Inc.; 65(6): pp. 557-63.

16. SEDOVA L, TOTHOVA V, OLISAROVA V, BARTLOVA S, CHLOUBOVA I, MICHALKOVA H, ET AL (2016) Opinions regarding the effectiveness of non-pharmacological measures in prevention of cardiovascular disease in the Czech Republic. Neuroendocrinol Letters.;37(Supplement 2): pp. 32-28.

17. YOUNG RF, KAHANA E (1993) Gender, recovery from late life heart attack, and med- ical care. Women Heal.;20(1):11-31.

18. LANE D, CARROLL D, RING C, BEEVERS DG, LIP GYH (2000) Effects of depression and anxiety on mortality and quality-oflife 4 months after myocardial infarction.; p. 49.

19. SURTEES PG, SASHIDHARAN SP (1986) Psychiatric morbidity in two matched community samples: a comparison of rates and risks in Edinburgh and St. Louis. J Affect Disord.; 10(2): pp. 101-13.

20. MARTENS EJ, SMITH OR, WINTER J, DENOLLET J, PEDERSEN SS (2008) Cardiac history, prior depression and personality predict course of depressive symptoms after myocardial infarction. Psychosom Med.; 38(2): pp. 257-64.

21. PEDERSEN SS, SMITH OR, DE VRIES J, APPELS A, DENOLLET J (2008) Course of anxiety symptoms over an 18-month period in exhausted patients post percutaneous coronary intervention. Psychosom Med.;70(3): pp. 349-55.

22. RODIN G, CRAVEN J, LITTLEFIELD C (1991) Depression and the medically ill: an integrated approach. New York: Brunner, Mazel;. p. 368.

23. CREED F (1999) The importance of depression following myocardial infarction. Heart.;82(4): pp. 406-8.

24. LESPERANCE F, FRASURE-SMITH N (1999) The seduction of death. Psychosom Med.;61(1): pp. 18-20.

25. ZIGMOND AS, SNAITH RP (1983) The Hospital Anxiety and Depression Scale. Acta Psychiatr Scand.;67(6): pp. 361-70.

26. MCDOWELL I (2006) Measuring Health: A Guide to Rating Scales. 3rd ed. New York: Oxford University Press;. p. 748.

27. BROOMFIELD NM, QUINN TJ, ABDULRAHIM AH, WALTERS MR, EVANS JJ (2014) Depression and anxiety symptoms post-stroke/TIA: Prevalence and associations in cross-sectional data from a regional stroke registry. BMC Neurol:;14(1): pp. 1-9.

28. HULLOVA D, DURIS R (2016) Slovak version of the Mini IPIP questionnaire [Internet]. Available from: http://ipip.ori.org/newItemTranslations.htm

29. TABACHNICK BG, FIDELL LS (2007) Using Multivariate Statistics. 5th ed. Pearson 
Education Inc.; p. 980.

30. MOSER DK, DRACUP K (1996) Is anxiety early after myocardial infarction associated with subsequent ischemic and arrhythmic events? Psychosom Med.;58(5): pp. 395-401.

31. MORRISON V, POLLARD B, JOHNSTON M, MACWALTER R (2005) Anxiety and depression 3 years following stroke: Demographic, clinical, and psychological predictors. J Psychosom Res.;59: pp. 209-13.

32. CRAWSHAW J, AUYEUNG V, NORTON S, WEINMAN J (2016) Identifying psychosocial predictors of medication non-adherence following acute coronary syndrome : A systematic review. J Psychosom Res. Elsevier B.V.;;90: pp. 10-32. 